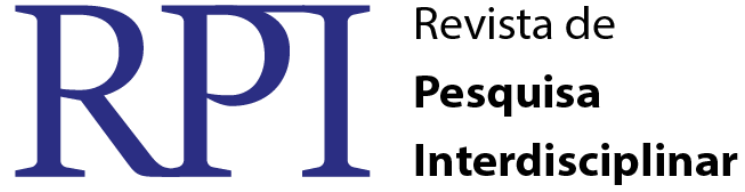

\section{ANTES SEM TERRA, HOJE COM TERRA E COM DIREITO A EDUCAÇÃO DE NÍVEL SUPERIOR}

\author{
Wirnaide Maria Rolim ${ }^{1}$ \\ Onireves Monteiro de Castro ${ }^{1}$
}

\begin{abstract}
RESUMO
O presente trabalho reflete sobre a importância do ensino superior para assentados rurais, grupo minoritário no âmbito universitário, apresentando contribuições que esta modalidade educacional pode oferecer no desenvolvimento do campo onde vivem os sujeitos pesquisados. Discute os principais desafios que os alunos assentados enfrentam para inserção e permanência na academia. Consiste em uma pesquisa descritiva, focada numa revisão bibliográfica e documental, foram consultados os seguintes teóricos e documentos: Fernandes (1999), Santos (2011), Bogo (2008), Moreira e Targino (1997), Caldart (2012), Molina (2008), INEP (2019), INCRA (2019). Através da pesquisa evidenciou-se que, a luta dos assentados pela terra, reflete na busca por outras conquistas: educação, saúde, lazer. A educação desenvolve produção do conhecimento, autonomia, criticidade, competências para o cumprimento das atividades do campo e o convívio em sociedade. As dificuldades enfrentadas pelos alunos estão associadas ao baixo poder aquisitivo, distância do local de trabalho/vivência e universidade, transporte, custeio de moradia, alimentação, aquisição de materiais didáticos e o distanciamento da realidade entre a universidade e os movimentos sociais. Conclui-se que, a educação é um fator transformador do campo, que é preciso formar parcerias entre: assentamentos rurais, Poder Público e movimentos sociais para fortalecer a luta pela garantia e a qualidade de ensino.
\end{abstract}

Palavras-chave: Educação. Assentamentos rurais. Ensino superior.

\section{BEFORE LAND, TODAY WITH EARTH AND WITH RIGHT TO EDUCATION OF SUPERIOR LEVEL}

\begin{abstract}
The present work reflects on the importance of higher education for rural settlers, a minority group in the university context, presenting contributions that this educational modality can offer in the development of the field where the researched subjects live. It discusses the main challenges that the settled students face for insertion and permanence in the academy. It is based on a descriptive research, focused on a bibliographical and documentary review, the following theoreticians and documents were consulted: Fernandes (1999), Santos (2011), Bogo (2008), Moreira and Targino (1997), Caldart (2008), INEP (2019), INCRA (2019). Through the research, it was evidenced that the struggle of the settlers for the land, reflected in the search for other achievements: education, health, leisure. Education develops production of knowledge, autonomy, criticality, competencies for the fulfillment of the activities of the field and the living in society. The difficulties faced by the students are associated with low purchasing power, distance from work / living and university, transportation,
\end{abstract}

\footnotetext{
${ }^{1}$ Universidade Federal de Campina Grande - UFCG.
} 
housing costs, food, acquisition of teaching materials and distance from reality between university and social movements. It is concluded that, education is a transforming factor of the field, that it is necessary to form partnerships between rural settlements, Public Power and social movements to strengthen the fight for the guarantee and the quality of education.

Keywords: Education. Rural settlements. Higher education.

\section{INTRODUÇÃO}

Os assentamentos rurais são espaços de reprodução da vida no campo, o resultado de muitas lutas sociais. Que permeiam diferentes modos de agir e pensar. Todos os assentados participam de todas as etapas dos processos produtivos, desde as plantações, colheitas, organização do assentamento, desenvolvimento econômico e cultural. Homens, mulheres, jovens, adolescentes e até crianças têm "papeis" definidos, os quais o fazem de forma efetiva na luta de classes e na formação do espaço, a partir da produção e reprodução social.

Para que se fortaleçam os vínculos entre a educação, de modo especial a superior e as lutas dos movimentos sociais faz-se preciso uma constante busca para transformar o campo num território de garantia de direitos e de afirmação da diversidade.

Pesquisas têm revelado que a cada dia cresce o número de assentados que buscam qualificação e formação superior, que os sujeitos em questão procuram melhorias na qualidade de vida nos assentamentos e consideram a educação como um dos grandes desafios, uma vez que estes necessitam enfrentar diversos entraves, entre eles: políticos, de locomoção, de ações contrárias a permanência na terra, de preconceito e desigualdade econômica.

O texto está ancorado em ideias relativas ao processo histórico de colonização, permanência, lutas e conquistas do homem no campo. Buscando compreender como a educação é essencial e necessária para completar o processo de assentamento rural.

A educação brasileira tem um histórico de evolução lento e desigual, sendo baseada em um pensamento elitizado de uma minoria, de modo conservador. Teve seu início com os Jesuítas no século XVI, que apenas alfabetizavam e só evolui anos depois, foi oferecida de modo prioritário às classes abastadas financeiramente, ficando a classe trabalhadora excluída do contexto educacional, só a partir do século XX que ocorre uma inserção das classes trabalhadoras e menos favorecidas para uma educação qualificada e em vários níveis, entre eles o superior.

Diante desta realidade, faz-se os seguintes questionamentos: Quais dificuldades enfrentadas por alunos de assentamentos rurais na Educação Superior? Quais as principais 
políticas públicas oferecidas aos alunos matriculados nessa modalidade educacional? Quais as contribuições da formação universitária para o desempenho dos assentados no processo de construção e evolução no campo?

Esse texto, baseia-se no pressuposto de que é preciso conhecer as possíveis oportunidades que as classes com menos poder econômico têm, garantindo um espaço na educação, principalmente a superior, de modo especial os assentados da Reforma Agrária, que vivem em assentamentos rurais.

Trata-se de uma pesquisa descritiva, focada em uma revisão bibliográfica e documental, construída de acordo com os referenciais encontrados em Fernandes (1999), Santos (2011), Bogo (2008), Moreira e Targino (1997), Caldart (2012), Molina (2008) e entre outros artigos. Recorreu-se também aos dados estatísticos sobre a realidade da educação superior em assentamentos rurais nos sites do INEP (2019), INCRA (2019).

Conhecer e refletir sobre a importância do ensino superior para assentados rurais, tidos como minoria no âmbito universitário, nos permite analisar objetivos, conceitos, e a evolução da educação superior no campo. Além do mais, as discussões apresentadas neste trabalho poderão servir de referência para que os assentados possam desenvolver possíveis soluções para aumentar a prática da formação superior e os trabalhos que desenvolvem no seu território.

Por fim, buscando uma compreensão melhor das ideias apresentadas neste trabalho, o mesmo está ordenado em texto contínuo e dividido em três grandes espaços. A parte introdutória contém os elementos da literatura, questões norteadoras, problematização e principais autores. Em seguida faz-se uma reflexão sobre os assentamentos rurais, sua história, suas lutas e seu processo de evolução e superação. Seguindo, analisa-se a importância da Educação Superior para os assentados e discute-se os desafios para entrar e permanecer na academia. Posteriormente apresenta-se as principais políticas públicas para essa modalidade de ensino. Finaliza-se com as considerações finais, apontando as principais reflexões obtidas.

\section{ASSENTAMENTOS RURAIS: UMA HISTÓRIA DE LUTAS E SUPERAÇÕES}

Os assentamentos rurais são resultados de um processo contínuo da desigualdade social no Brasil, onde o rico tem muito e o pobre nada tem. Conhecer a evolução da luta camponesa ao longo da história é analisar as múltiplas facetas que envolvem essa conquista, 
observa-se a divisão desigual, quase sempre voltada aos que tem maior poder econômico, das terras brasileiras desde seus primórdios, a luta dos menos favorecidos, os inúmeros conflitos e as conquistas atuais.

O Brasil é um país de grandes dimensões territoriais, porém com um histórico de muita desigualdade na divisão de terra. Observa-se que desde o chamado descobrimento e o processo de colonização pelos portugueses os que tinham maior poder aquisitivo foram beneficiados e os menos favorecidos, nativos e portugueses trazidos para o Brasil, passaram somente a trabalhar na terra sem direito de ser seu dono.

Pode-se perceber que desde o início com a retirada total da terra dos índios, as divisões das capitanias hereditárias, os grandes engenhos, as fazendas de café, entre outros, o intuito foi sempre de exploração das terras que gerassem benefícios aos governantes da coroa e por isso, eram comuns a existência de muita terra para poucos donos. Esse foi um dos principais conflitos da luta pela terra.

Com isso, Fernandes (1999, p. 15) relata que:

A história da formação do Brasil é marcada pela invasão do território indígena, pela escravidão e pela produção do território capitalista. Nesse processo de formação de nosso País, a luta de resistência começou com a chegada do colonizador europeu, há 500 anos, desde quando os povos indígenas resistem ao genocídio histórico. Começaram, então, as lutas contra o cativeiro, contra a exploração e, por conseguinte, contra o cativeiro da terra, contra a expropriação, contra a expulsão e contra a exclusão, que marcam a história dos trabalhadores desde a luta dos escravos, da luta dos imigrantes, da formação das lutas camponesas. Lutas e guerras, uma após a outra ou ao mesmo tempo, sem cessar, no enfrentamento constante contra o capitalismo.

Observa-se que o processo da luta pela terra é histórico, e sempre existiu uma relação de exploração: ricos x pobres, responsáveis pela terra (donatários, arrendatários) x coroa portuguesa, pois os que recebiam o direito de trabalhar na terra e deixa-la como herança a seus filhos, eram obrigados a pagar diversos impostos a coroa portuguesa como: a Carta de Foral, o Quinto, a Derrama, etc. (AMED e NEGREIROS,2000).

A partir da década de 40, tem o surgimento e desenvolvimento da Revolução Industrial, ancorada em teorias que visavam à eficiência do trabalho e a produtividade em massa. Esse processo faz com que as pessoas do campo migrem para as cidades em busca de empregos e melhores condições de vida, o êxodo rural. No entanto as cidades não estavam preparadas para o aumento em massa da população, com aglomerações em diversas partes do 
Brasil. Um aumento significativo de camponeses pobres, sem terra e sem lugar para morar, vivendo em condições sub-humanas nas cidades.

A partir da década de 60 , com o processo econômico e político de modernização tecnológica da agricultura, que os entraves pela terra se fortaleceram. Os grandes latifundiários trocam o homem do campo, responsável pela maior parte do trabalho na terra pelas máquinas e, o trabalhador, fica sem emprego e sem terra, até mesmo para produzir seu próprio sustento.

Com tantos problemas no campo a partir dos anos 60 fortaleceram-se as lutas camponesas e os debates sobre a Reforma Agrária. Surgem então os movimentos populares em resistência aos problemas que a maior parte da população camponesa enfrentava. No ano de 1964 surgem no Brasil as CEB's - Comunidades Eclesiais de Base, que apoiam de modo efetivo as causas sociais, fundamentadas na Teologia da Libertação e se espalham por todo território.

\begin{abstract}
A quase totalidade dos movimentos populares rurais atuais no Brasil surgiu como resistência a um processo econômico e político que provocou a rápida modernização da agricultura. Os problemas vividos pela maioria da população rural, em particular os trabalhadores assalariados, os camponeses e as suas famílias, por trás das variadas formas de sua integração, exploração e marginalização, que aprofundam a desigualdade, não são devidos à "falta" de desenvolvimento, mas, ao contrário, ao "sucesso" do modelo modernizador. Na verdade, a desigualdade e a exclusão no campo existiam desde antes do processo de modernização, mas através deste processo reproduziram-se em escala ampliada. A resistência dos trabalhadores rurais mostrou para a sociedade como um todo o caráter ao mesmo tempo antidemocrático e antiecológico de tal desenvolvimento. (GRZYBOWSKI, 2013, p.346-347).
\end{abstract}

Porém, os militares assumiram o controle político do Brasil em 1964 juntamente com a elite fundiária, banqueiros e empresários, com eles vem uma época de retrocessos e repressão, onde os camponeses são cada vez mais perseguidos, torturados, muitos assassinados e desestimulados a lutar pela terra.

Segundo, Fernandes (1999, p.30):

O golpe acabou com a democracia e, por conseguinte reprimiu violentamente a luta dos trabalhadores. Os movimentos camponeses foram aniquilados, os trabalhadores foram perseguidos, humilhados, assassinados, exilados. Todo o processo de formação das organizações dos trabalhadores foi destruído. Igualmente significou a impossibilidade dos camponeses ocuparem seu espaço político, para promoverem por seus direitos, participando das transformações fundamentais da organização do Estado brasileiro. O golpe significou um retrocesso para o País. Os projetos de 
desenvolvimento implantados pelos governos militares levaram ao aumento da desigualdade social. Suas políticas aumentaram a concentração de renda, conduzindo a imensa maioria da população à miséria, intensificando a concentração fundiária e promovendo o maior êxodo rural da história do Brasil.

Foi no Período Militar, que se institui a Lei 4.504/1964, que cria o Estatuto da Terra. O Estatuto determina que a terra tem uma função social e deve gerar renda. Necessariamente deve ser utilizada para produção de alimentos e para o trabalho do campo, deste modo considerada produtiva. Conforme Art. 2 - Lei 4.504/1964:

Art. $2^{\circ}$ : É assegurada a todos a oportunidade de acesso à propriedade da terra, condicionada pela sua função social, na forma prevista nesta Lei.

$\S 1^{\circ}$ A propriedade da terra desempenha integralmente a sua função social quando, simultaneamente:

a) favorece o bem-estar dos proprietários e dos trabalhadores que nela labutam, assim como de suas famílias;

b) mantém níveis satisfatórios de produtividade;

c) assegura a conservação dos recursos naturais;

d) observa as disposições legais que regulam as justas relações de trabalho entre os que a possuem e a cultivem.

Esta Lei determina os critérios para a avaliar os padrões produtivos x improdutivos. Se considerada improdutiva e não os obedecendo ao padrão, os grandes latifúndios são destinados à Reforma Agrária (SANTOS, 2011). Para avaliar os critérios exigidos pela Lei foi criado o Instituto Nacional de Desenvolvimento Agrário - (INDA) e depois em 1970 foi mudado para Instituto Nacional de Colonização e Reforma Agrária - (INCRA).

No ano de 1975, origina-se a Comissão Pastoral da Terra (CPT), que vem auxiliar os camponeses a conquistarem espaço na luta pela Reforma Agrária. Em 1984, surge o Movimento dos Trabalhadores Rurais Sem-Terra (MST), tendo por objetivos lutar pela terra, lutar por Reforma Agrária e lutar por uma sociedade mais justa e fraterna.

O MST sempre teve como referências estes princípios: lutar contra o capital na construção de uma sociedade sem exploração; lutar pela terra e pela reforma agrária, para que a terra esteja sempre a serviço de toda a sociedade; lutar pela dignidade humana, por meio da justa distribuição da terra e das riquezas produzidas pelo trabalho; lutar sempre pela justiça com base nos direitos humanos; lutar contra todas as formas de dominação. (SANTOS 2011, p.77).

As lutas se fortalecem e começam a dar resultados. Em princípio, os acampamentos cheios de conflitos, dificuldades e muita burocracia (documentação necessária para comprovar latifúndio pela quantidade de terra e improdutivos) pelo INCRA.

RPI Revista de Pesquisa Interdisciplinar, v. 4, e4003, 2019. 
Depois com todos os requisitos preenchidos e legalizados de todas as ordens vem os assentamentos. Ao receberem a terra, as famílias passam para uma nova fase da vida, de trabalho, transformando o assentamento em um local produtivo com novas oportunidades.

As novas descobertas estão em torno de práticas em processos diferenciados e em constante dinâmica. Essas estratégias conferem características do modo de vida camponês: seu modo de trabalho ligado direto ao campo, de vida, em forma de comunidade, que se organiza e luta por direitos como Educação, saúde, lazer. Do dever de permanecer na terra como forma de garantir o direito a ela. Neste viés, Moreira e Targino (1997, p.295) afirmam que:

Para o homem do campo, a terra representa não apenas a possibilidade de sua sobrevivência, mas também a garantia de poder permanecer com sua família no seu local de origem, livre da sujeição do cambão ou do trabalho alugado. A terra constitui ainda para o camponês o único bem e a única herança passível de ser deixada para a família. Em outras palavras, a terra confere dignidade ao pequeno produtor.

Permanecer no campo é muito importante, para um assentado, seus filhos e para o MST, pois é sinal de continuidade na luta pela terra "dono enquanto estiver na Terra". A luta continua e a cada momento novas conquistas precisam ser almejadas. É preciso que essa luta pela terra se estenda a outras conquistas de direitos como: a saúde de qualidade, a educação de forma continuada, do básico à universidade, ao lazer e todos os direitos que são garantidos aos cidadãos do país.

A educação é fundamental, e uma formação superior é garantia de progresso para a terra conquistada, sabendo-se que essa "conquista" está ligada à sua permanência na terra através do termo de posse que assegura ao assentado ser dono enquanto ali permanecer, ele e seus descendentes. Diante disso, a educação é parte dessa luta, pois "é a escola que garante o aprendizado da tradição” (BOGO, 2008, p. 108). Sem educação não há progresso.

\section{DESAFIOS NO ENSINO SUPERIOR PARA ALUNOS DE ASSENTAMENTOS RURAIS}

A organização da classe trabalhadora rural, faz ponto de partida para muitas lutas. Essas organizações são conjuntas e buscam a transformação do seu habitat, na sociedade e das relações de produção e reprodução do campo. Dessa forma, Bogo (2008, p. 10).), ainda considera que: 
Para que os dominados se emancipem, precisam formar e organizar a sua classe, reconhecer a existência do seu oposto que é a classe dominante, e, a partir disso, procurar através da luta, ocupar o seu lugar, ultrapassar a natureza da dominação burguesa, minoritária e instituir a democracia da maioria para a maioria, pondo em movimento a lei da dialética da quantidade e qualidade

Para os camponeses de assentamentos rurais, a educação é um caminho para o futuro, que abre um leque de possibilidades, conquistar no presente para garantir um futuro cada vez melhor. Porém muitos são os desafios enfrentados por assentados rurais para chegar ao ensino superior e também grandes são os entraves para permanecer e concluir seus objetivos.

Do ponto de vista dos movimentos sociais faz parte da construção de um outro referencial de campo e de sociedade, conceber também uma outra educação, que possa contribuir para a formação de seres humanos transformadores. Historicamente, a educação segue um modelo proposto pelos poderes hegemônicos na sociedade e atua no sentido de sua reprodução e manutenção, refletindo inclusive as suas contradições, trazendo consigo a marca da exclusão e do privilégio. As desigualdades educacionais, principalmente no que tange ao acesso e à qualidade, se instauraram nos diversos níveis de escolarização e, em especial, no ensino superior. Por questões de classe, gênero e etnia, um grande número de jovens vem sendo excluídos do ensino superior (BATISTA, CORREIA e BRITO 2010 p. 9).

Dentre vários desafios que são enfrentados por alunos de assentamentos rurais no âmbito universitário destaca-se:

As longas distâncias que existem entre os assentamentos rurais onde moram e trabalham, e o local de estudo, as universidades, dificultam a forma acesso e de permanência destes estudantes, que geralmente enfrentam problemas com transporte, custeio de moradia, alimentação e aquisição de materiais didáticos.

Outro fator relevante é o baixo poder aquisitivo dos estudantes, que na maioria das vezes são responsáveis por parte da renda familiar, ou mesmo responsáveis diretos por uma família nos assentamentos onde residem. Nesse contexto Caldart, (2012, p. 221 e 222) afirma que:

Entre os fatores externos, um dos problemas centrais são as desigualdades socioeconômicas e étnico-raciais que estruturam a sociedade brasileira. Embora a educação seja vista, tanto pelo senso comum quanto por especialistas, como um fator essencial para a melhoria das condições de vida, a verdade é que no Brasil a expansão do ensino ocorreu num quadro de permanente e profunda concentração de renda. Os indicadores educacionais, interpretados conjuntamente com os dados socioeconômicos, étnico raciais e 
territoriais, demonstram que o padrão brasileiro de exclusão causa impacto na apropriação da oferta educacional.

O preconceito por pertencer a comunidades rurais ainda é fator agravante para jovens de assentamentos, mesmo usando roupas semelhantes, gosto musicais ou intelectuais iguais ainda são visto como caipiras ou menos dotados de conhecimento, algo que atrapalha a permanência na academia.

Existe ainda um distanciamento entre a universidade e os movimentos sociais, que apesar de lutar por uma educação qualificada abriga uma quantidade muito grande de pessoas que vivem de forma elitizada e muitas vezes preconceituosa.

Para garantir a participação ativa dos assentados da reforma agrária e alcançar uma aprendizagem significativa, a educação deverá criar um ambiente de diálogo entre as universidades e o campo, em que o aluno tenha a oportunidade de manifestar-se e dialogar com os temas propostos, criando um modo de pensar igualitário.

Esses e outros fatores compreende-se como determinantes que podem inviabilizar a permanência, a aprendizagem e a conclusão do curso pelos estudantes.

\section{PRINCIPAIS POLÍTICAS PÚBLICAS NO ENSINO SUPERIOR NA REFORMA AGRÁRIA}

A educação do campo é fundamental e faz parte da luta do campones, na busca por igualdade, de direitos adquiridos, por condições de superação do espaço agrário, que é mutável e dinâmico. Vale frisar que o termo Educação do Campo não refere-se apenas a o local onde se localiza a escola ou o processo formativo, mas a um modo de vida um espaço delimitado por muita luta.

(...) nomeia um fenômeno da realidade brasileira atual, protagonizado pelos trabalhadores do campo e suas organizações, que visa incidir sobre a política de educação desde os interesses sociais das comunidades camponesas. Objetivos e sujeitos a remetem às questões do trabalho, da cultura, do conhecimento e das lutas sociais dos camponeses e ao embate (de classe) entre projetos no campo e entre suas lógicas de agricultura que implicam no projeto de país e de sociedade e nas concepções de política pública, de educação e de formação humana (CALDART, 2012, p. 259).

O termo Educação do Campo surge e é fortalecido na I Conferência Nacional por uma

Educação Básica do Campo, que ocorre no ano de 1998. Neste mesmo ano é criado o RPI

Revista de Pesquisa Interdisciplinar, v. 4, e4003, 2019. 
PRONERA - Programa Nacional de Educação na Reforma Agrária, esse programa faz parcerias entre o governo, as instituições de ensino e os movimentos sociais.

Hoje a Educação do Campo é garantida por lei, sendo regulamentada por decretos e resoluções, Entre esses marcos regulatórios destacamos: a Constituição da República Federativa do Brasil, nos art. 205, 206 e 207; o Plano Nacional de Educação para o decênio 2011-2020 (PNE - 2011/2020), a Lei de Diretrizes e Bases (BRASIL, 2018). O Decreto 7.352 de 2010, (BRASIL, 2010), que institui a Educação do Campo e o PRONERA como política pública, Art. $1^{\circ}$ - destina-se à ampliação e qualificação da oferta de educação básica e superior às populações do campo.

O PRONERA foi criado em 1998, pela Portaria $n^{\circ} 10$ de 16 de abril de 1998, sendo coordenado pelo Instituto Nacional de Colonização e Reforma Agrária (INCRA), por ter atuação direta com os movimentos sociais, o programa do governo federal tem por objetivo reduzir entre os trabalhadores rurais jovens e adultos que vivem em acampamentos e assentamentos o alto índice de analfabetismo, elevar o nível de escolarização regular, incentivando o acesso ou nível médio, técnico e superior.

Como Política Pública o PRONERA destaca-se por favorecer pessoas de baixa renda e do campo, incentivando ao direito a educação de qualidade e em todos os níveis. De acordo com Molina (2008, p. 42), como “(...) política pública institucionalizada por demanda coletiva, o PRONERA carrega em si grande aprendizado, por meio de parceria”. Trabalhando de forma conjunta com as instituições de ensino, o governo e o assentado de reforma agrária.

O PRONERA é fundamentado em princípios pedagógicos indissolúveis da educação e do desenvolvimento sustentável, que visa a qualificação de vida das pessoas envolvidas neste contexto. São Princípios Político-Pedagógicos do PRONERA:

a) Democratização do acesso à educação: a cidadania dos jovens e adultos que vivem nas áreas de reforma agrária será assegurada, também, por meio da oferta de uma educação pública, democrática e de qualidade, sem discriminação e cuja responsabilidade central seja dos entes federados e suas instituições responsáveis e parceiras nesse processo.

b) Inclusão: a indicação das demandas educativas, a forma de participação e gestão, os fundamentos teóricos metodológicos dos projetos devem ampliar as condições do acesso à educação como um direito social fundamental na construção da cidadania dos jovens e adultos que vivem nas áreas de reforma agrária.

c) Participação: a indicação das demandas educacionais é feita pelas comunidades das áreas de reforma agrária e suas organizações, que em conjunto com os demais parceiros decidirão sobre a elaboração, execução e acompanhamento dos projetos.

d) Interação: as ações desenvolvidas por meio de parcerias entre órgãos governamentais, instituições de ensino públicas e privadas sem fins 
lucrativos, comunidades assentadas nas áreas de reforma agrária e as suas organizações, no intuito de estabelecer uma interação permanente entre esses sujeitos sociais pela via da educação continuada e da profissionalização no campo.

e) Multiplicação: A educação do público beneficiário do PRONERA visa a ampliação do número de trabalhadores rurais alfabetizados e formados em diferentes níveis de ensino, bem como, garantir educadores, profissionais, técnicos, agentes mobilizadores e articuladores de políticas públicas para as áreas de reforma agrária.

f) Participação social: o PRONERA se desenvolve por meio de uma gestão participativa, cujas responsabilidades são assumidas por todos os envolvidos na construção, acompanhamento e avaliação dos projetos pedagógicos. A parceria é condição essencial para a realização das ações do PRONERA. Os principais parceiros são os movimentos sociais e sindicais do campo, as instituições de ensino públicas e privadas sem fins lucrativos e os governos municipais e estaduais (INCRA,2011)

Dados estatísticos são oferecidos para demostrar que está sendo feito um avanço na educação dos assentados, no entanto, é preciso que estes números sejam cada vez maiores e que a educação superior seja reforçada, como garantia de que as terras conquistadas possam ter um progresso significativo, com novas tecnologias e aproveitamento favorável aos pequenos produtores dos assentamentos.

Em 2015, o Relatório Final da II Pesquisa Nacional de Educação nas áreas de Reforma Agrária (II PNERA)1, realizada conjuntamente entre o INCRA, o IPEA (Instituto de Pesquisa Econômica Aplicada) e a Cátedra UNESCO de Desenvolvimento Territorial e Educação do Campo (UNESP), concluiu que no período de 1998 a 2011 foram beneficiados 164.894 educandos oriundos dos assentamentos de reforma agrária federal. Nesse período, foram realizados 320 cursos por meio de 82 instituições de ensino em todo o País, sendo 167 de Educação de Jovens e Adultos Fundamental, 99 de nível Médio e 54 de nível Superior. Os 320 cursos foram realizados em 880 municípios, em todas as unidades da federação. (INCRA, 2011)

A educação é um espaço social no qual os conhecimentos são transmitidos, nesse sentido, deve ser um direito para todos os cidadãos em idade escolar e de responsabilidade do Estado e da família. A educação é vista pela sociedade como um lugar privilegiado para socializar conhecimentos e formar opiniões, desta forma deve apresentar parâmetros sobre o quanto ainda pode ser feito para refletir a história, a cultura e os aspectos sociais de seu país.

\section{CONSIDERAÇÕES FINAIS}

A educação é um fator transformador e proporciona ao assentado rural a convivência com a diversidade, com a desigualdade, com diferentes modos de observar o mundo a nossa RPI

Revista de Pesquisa Interdisciplinar, v. 4, e4003, 2019. 
volta, proporciona ainda o enriquecimento entre a relação campo e universidade. Podendo oferecer importante apoio no desenvolvimento e evolução da organização do campo.

Mostra que entre a realidade que se imagina e a realidade que apresenta a educação, existe a necessidade de uma ação efetiva do poder público na organização do espaço educacional do campo, como também da efetivação do que se aprende em uma Unidade Acadêmica para a vivência em um assentamento rural.

Considerando que a educação, de modo especial a superior é de fundamental importância para a Reforma Agrária e os assentamentos rurais e demostrando que essa educação vem dar suporte ao ato de conhecer e vivenciar a realidade do campo, assim como também uma análise da ação positiva, consciente e significativa para o desenvolvimento sustentável de qualidade na área rural.

Conclui-se que é preciso formar parcerias com a comunidade rural, o Poder Público em todas as esferas responsáveis e principalmente uma organização específica dos assentados para fortalecer a luta pela garantia e a qualidade de ensino. Faz-se necessário políticas públicas efetivas que valorizem a qualificação do assentado. Como também o assentado ter dedicação e utilizar-se de todos os conhecimentos oferecido seja em um curso de graduação, uma especialização para tornar-se um profissional pesquisador para assim oferecer uma melhor qualidade de vida e que esta seja, Critica, Reflexiva e principalmente Cidadã.

\section{REFERÊNCIAS}

AMED, Fernando José; NEGREIROS, Plínio José Labriola de Campos. História dos Tributos do Brasil. São Paulo: Edições SINAFRESP, 2000.

BATISTA, Maria do Socorro Xavier, CORREIA, Deyse Morgana das Neves, BRITO. Rosa Maria de Jesus. Educação na reforma agrária: visando o desenvolvimento sustentável das áreas de assentamentos no brasil - VIII Congresso Latino Americano de Sociologia Rural, Porto de Galinhas, 2010.

BOGO, Ademar. Identidade e luta de classes. São Paulo: Expressão Popular, 2008.

BRASIL. Decreto $n^{\circ} 7.352$, de 04 de novembro de 2010 - Dispõe sobre a política de educação do campo e o Programa Nacional de Educação na Reforma Agrária - PRONERA.

BRASIL. Lei de Diretrizes de Base da Educação Nacional - 9394/96 - Estabelece as diretrizes e bases da educação nacional.

BRASIL. Lei N. ${ }^{\circ}$ 8.035, DE 2010. Aprova o Plano Nacional de Educação para o decênio 2011-2020 e dá outras providências.

RPI Revista de Pesquisa Interdisciplinar, v. 4, e4003, 2019. 
CALDART, Roseli. Educação do Campo. In: CALDART, Roseli Salete; PEREIRA, Isabel Brasil; ALENTEJANO, Paulo; FRIGOTTO, Gaudêncio (Orgs.). Dicionário da Educação do Campo. Rio de Janeiro: Escola Politécnica de Saúde Joaquim Venâncio; São Paulo: Expressão Popular, 2012.

FERNANDES, Bernardo Mançano. Contribuição ao Estudo do Campesinato Brasileiro: formação e territorialização do Movimento dos Trabalhadores Rurais Sem Terra - MST (1979-1999). Tese (Doutorado em Geografia) Faculdade de Filosofia, Letras e Ciências Humanas, Universidade de São Paulo, 1999.

GRZYBOWSKI, Cândido. Movimentos populares rurais no Brasil: desafios e perspectivas: In STEDILE, João Pedro (Org.), A questão agrária no Brasil: o debate na década de 1990. 1 ed. São Paulo: Expressão popular, 2013.

INCRA. Instituto Nacional De Colonização E Reforma Agrária. PRONERA, Manual de Operações, 2011.

INCRA. Instituto Nacional De Colonização E Reforma Agrária. PRONERA, Manual de Operações, 2004.

INEP. Instituto Nacional de Estudos e Pesquisas Educacionais Anísio Teixeira. Sinopse estatística da Educação Superior 2016. Brasília, 2018. Disponível em: < http://portal.inep.gov.br/web/guest/sinopses-estatisticas-da-educacao-superior>. Acesso em: 01 out. 2018.

MOLINA, Mônica Castagna. A Constitucionalidade e a Justicibilidade do Direito à Educação dos Povos do Campo. In: SANTOS, Clarice Aparecida (Org). Por uma Educação do Campo-Políticas Públicas. Caderno 7, Brasília, 2008.

SANTOS, Júlio César Borges dos. O movimento dos trabalhadores rurais sem-terra e as relações entre saúde, trabalho e ambiente em um assentamento rural no estado do Rio de Janeiro. Dissertação (Mestrado) - Escola Nacional de Saúde Pública Sergio Arouca, Rio de Janeiro, 2011.

TARGINO, Ivan, MOREIRA, Emília. MENEZES, Marilda. As ligas camponesas na paraíba um relato a partir da memória dos seus protagonistas. Ruris, Volume 5, número, 2011. 